\title{
Improving Periodic Preventive Maintenance Strategies Using Condition Monitoring Data
}

\author{
Guro Ravnestad ${ }^{1}$, Sukhvir Singh Panesar ${ }^{2}$, Dina Kayrbekova $^{2}$, and Tore Markeset ${ }^{2}$ \\ ${ }^{1}$ Apply Sørco, P.O. Box 8040, 4068 Stavanger, Norway \\ \{guro.ravnestad, sukhvir.singh. panesar\} @applys $\varnothing$ rco.no \\ ${ }^{2}$ University of Stavanger, N-4036 Stavanger, Norway \\ \{dina.kayrbekova, tore.markeset\}@uis.no
}

\begin{abstract}
Due to reduction in petroleum production and aging production facilities, the Norwegian oil and gas industry is interested in optimization maintenance strategies and reducing costs. Currently the maintenance strategies are based on predetermined periodic (calendar or use time) preventive maintenance strategies that are developed based on statistical data and/or recommendation from the manufacturers. One possibility currently being explored is to use condition monitoring data available in the process monitoring system, to update and improve the predetermined periodic preventive maintenance strategies. Furthermore, we discuss some issues and challenges of the integration of available condition monitoring data in the planning and optimization of predetermined preventive maintenance strategies.
\end{abstract}

Keywords: Predetermined periodic preventive maintenance, Condition based predictive maintenance, Maintenance strategy.

\section{$1 \quad$ Introduction}

Globalization, high customer needs and tough competition force companies to reduce the production downtime and increase the reliability and performance of their equipment [1]. This is also the case in the oil and gas industry on the Norwegian Continental Shelf (NCS) where there is an increasing focus on the development of maintenance strategies that are cost-effective and efficient as well as reducing risks to health, safety and environment (HSE). Generally, the maintenance routines are developed based on the generic maintenance strategies, best practices, manufacturers' recommendations, etc., and are tailor-made for each installation. Currently, on many of the older offshore installations, the preventive maintenance programs are mainly predetermined periodic based (calendar time or operational use). However, many researchers recommend maintenance strategies based on the real asset condition [2], [3] where condition monitoring data enables proactive planning and optimization of maintenance activities based on the real equipment degradation.

In recent decades there has been a change in how the industry handles maintenance partly due to the development in information and communication technology (ICT) 
[4]. Furthermore, recent advances in sensor- and inter-communication technology have enabled the collection and interpretation of useful information concerning the equipment health. It is possible to generate data that gives valuable information about the asset condition [5]. The inherent advantage with this kind of strategy is that some of the redundant maintenance activities can be avoided, thus optimizing maintenance strategies.

However, the limitation is often the lack of appropriate sensor technology designed for petroleum production facilities which have set requirements with respect to explosion-proof technology. Also, the sensor technology is mainly developed on rotary equipment, but static equipment still lacks robust sensors and remote control technology [6]. The condition of such assets can mainly be assessed by inspections which are expensive and prone to risks as well as subject to individual judgments [7], [8]. However, on oil and gas facilities there is a large amount of instrumentation. This may possibly provide a large source of information concerning the condition and state of the equipment if efforts are taken to explore the possibilities of using the information for the purpose of equipment condition and health assessment.

Much research has been performed with respect to the development of preventive maintenance programs [9-11]. There also exists abundant literature on condition monitoring at equipment level as well as for single systems [12], [13]. However, the literature is scarce for the development of CBM on multi-systems as well as for the development of dynamic preventive maintenance strategies.

Based on a study in the Norwegian oil and gas industry and on a literature review, this paper identifies and discusses some of the issues, opportunities and challenges concerning the integration of condition monitoring data to improve the effectiveness and efficiency of predetermined periodic preventive maintenance strategies.

\section{Maintenance Practices on the NCS}

The Norwegian oil and gas industry has a high focus on maintenance strategies, both in planning and performance. In addition to the stringent regulations being set for new installations, installations that outlive their initial design life as a result of improved drilling technologies are placed under strict safety demands through national and international standards. The use of integrated operations in the maintenance activities is increasing, and more and more maintenance activities can be performed and/or planned from onshore communication and control posts [14]. The integration of operation and maintenance activities is constantly revised.

Developing effective and efficient maintenance strategies is essential to a company operating in the oil and gas industry wishing to ensure safe, effective and efficient production processes and profitability. Through defining maintenance goals and objectives and formulating maintenance strategies, the company can reach the overall aim of creating value by ensuring the highest possible HSE levels, increasing the reliability of the production, ensuring cost effectiveness, and increasing the competitive ability of the company [15]. Offshore maintenance activities are based on the company's overall maintenance strategy and in some cases on specific maintenance strategies for certain types of equipment. 
Safe operations and prevention of accidents is a regulatory requirement. The safety of the installation, systems and the equipment is a responsibility of the operator companies. No comprises can be made on the safety related issues. Furthermore, the equipment connected to the safety functions and/or barrier system become part of the critical equipment. In addition to the equipment failure modes, the availability and performance requirements influence the maintenance requirements of such equipment. The safety requirements influence the facility, system and equipment performance and thus the maintenance needs. The important step in the optimization process is to identify the maintenance needs based on the performance requirements and on the needs to maintaining the technical condition of the equipment. Once the maintenance needs are identified then "just sufficient" maintenance activities are planned and executed at "just in time" to minimize or reduce the unexpected equipment failures. Maintenance strategies developed and implemented with this philosophy can help in optimization of maintenance on a facility.

\subsection{Predetermined Periodic (Time or Use Based) Preventive Maintenance}

Preventive maintenance is planned maintenance that aims to mitigate wear by maintaining the equipment from the start, and throughout all, of its operating lifetime [10]. Studies have shown that this fashion of operation costs about $\$ 13$ per horsepower per year [16]. Preventive maintenance activities can be either calendar time based or operational use based, meaning that the maintenance activities planned are based on either fixed time intervals or on accumulated operational/running time. The key objective in this strategy is to perform improvement and restorative maintenance before the equipment breaks down or no longer performs to the originally set standards. The preventive maintenance strategy allows maintenance activities to be planned and executed at times when the impact of downtime will be the least.

Different types of equipment acquire different maintenance intervals based on frequency of failure and failure criticality. One of the challenges in preventive maintenance is to set the right interval. It is essential to ensure that: 1) Costly and unnecessary maintenance activities are not performed long before maintenance is actually needed; 2) Costly corrective failures do not occur due to too long intervals between planned preventive maintenance activities [17].

Companies delivering maintenance or condition monitoring services often also offer analyses to find such best time intervals. These intervals are normally based on manufacturers' recommendations, general industry recommendations, governing rules and regulations, statistical data and experience.

\subsection{Condition Based (Predictive) Preventive Maintenance}

Condition based predictive maintenance is a systemized maintenance strategy that aims to forestall failure based on tracking the performance or state of a piece of equipment. Predictive maintenance aims to run equipment for as long as possible before maintenance is performed through planning and executing maintenance activities based on condition monitoring data and estimates of wear development based on historical data and experience as well as statistical information. 
Condition monitoring is defined in [18] as "the continuous or periodic measurement and interpretation of data to indicate the degraded condition (potential failure) of an item and the need for maintenance". Beebe [13] explains that "condition monitoring, on- or offline, is a type of maintenance inspection where an operational asset is monitored and the obtained data analyzed to detect signs of degradation, diagnose cause of faults, and predict how long it can be safely or economically run". The aim of condition monitoring is to be able to provide condition based maintenance, increasing the functional lifetime of the asset and decreasing the life cycle costs [19].

Condition monitoring of equipment can be performed manually, automatically or as a mix of the two, and concerns all processes of gaining, transforming and interpreting data concerning the state of equipment or processes. Physical features of the equipment are monitored using different types of sensors and instrumentation. Such features can be process variables like pressure, flow and temperature, or equipment variables such as vibration.

Offline condition monitoring refers to such measurements being taken repeatedly in set time intervals, often performed by specialists physically going out in the field to take the measurements or by process workers familiar with the technology and equipment. Online condition monitoring refers to the sampling of measurements in a continuous manner, with sensors and transponders connected to the equipment sending the signal in real time.

The choice of utilizing on- or offline condition monitoring is based on several factors, the most important of them being:

- The rate of change in the feature that is to be measured

- The criticality of the equipment with respect to HSE factors

- The criticality of the equipment with respect to production

- The expected mean time before failure (MTBF)

The idea is to monitor and log machinery and equipment performance through key performance indicators in order to predict maintenance demands early. One can thus estimate how the degradation evolves and the performance decreases over time. Through using such performance indicators one can measure the performance of the equipment and compare the results with initial performance levels. Thus the output is found, and analysis can determine the equipment condition. When performance degradation is observed the organization can start planning appropriate compensative maintenance activities and execute them at a time convenient for the management and projection plans before the actual failure event, as shown in Figure 1a [20].

By utilizing predictive maintenance one can schedule maintenance activities when the potential production losses are minimal, thus decreasing the total cost of the maintenance activity. Figure $1 \mathrm{~b}$ illustrates that the speed of performance degradation is important. If the failure is instantaneous, as in curve A, the failure is difficult if not impossible to predict using condition monitoring. If the performance degradation is as shown in curves $\mathrm{B}$ and $\mathrm{C}$, one may choose continuous or periodic condition monitoring respectively, also dependent on the criticality of the equipment. 




a) Performance degradation vs. time

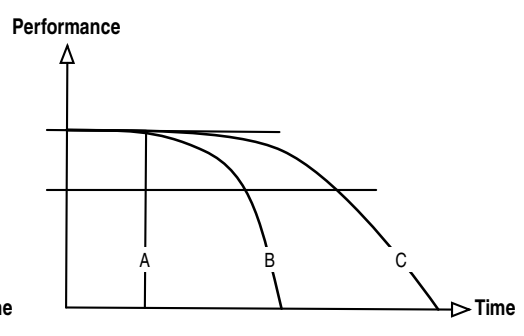

b) Performance degradation speed vs. time

Fig. 1. System performance degradation: a) Performance degradation and failure vs. time; b) Performance degradation speed vs. time [20]

\section{Potential of Using Condition Monitoring to Improve Periodic Preventive Maintenance}

An integrated maintenance scheme is being developed with and alongside condition monitoring and is believed to have great potential. The advantage of this method is that downtime due to maintenance is reduced as activities are not performed when they are not needed, and an increase in uptime can be achieved, as shown in Figure 2. If properly implemented, this strategy would yield longer time for planning activities and purchasing spare parts, decreasing the need for large and/or expensive spare parts inventories. As maintenance work can be planned for in advance, activities can be planned at the opportune moment with respect to production and availability of personnel, as shown in Figure 2.

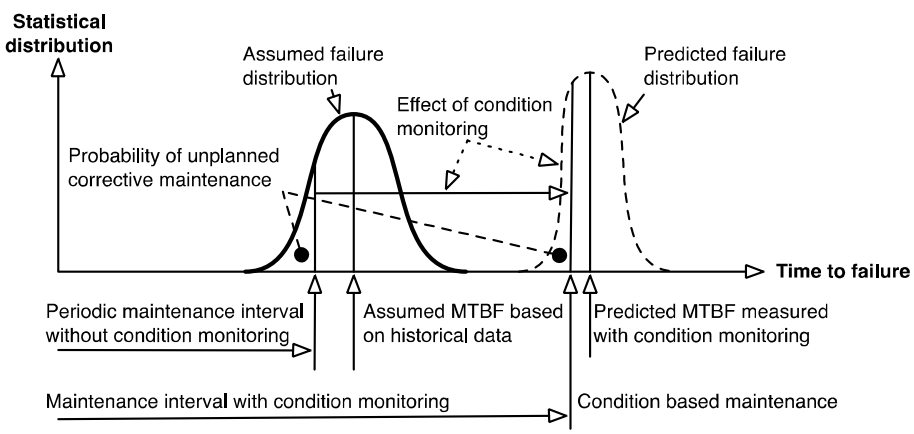

Fig. 2. Periodic maintenance based on assumed failure distribution and maintenance based on monitoring of real performance degradation and condition [20]

The disadvantages of this method are that unnecessary maintenance work might be performed if the degradation of the equipment is not correctly assessed. A need for post-maintenance maintenance might occur due to the break-in of new components, improper assembly or failures induced during maintenance [17]. Furthermore, the probability of detecting the failure is never $100 \%$, and failures requiring expensive 
correction may occur [20]. In addition, by introducing more sensors and instrumentation, one also increases the complexity of the system, and one may experience sensor or instrumentation failures as well. Predictive maintenance also requires that the maintenance workers have skills and competence in condition monitoring practices, techniques and analysis to be able to take full advantage of the methods. Thus, either an adequate training program needs to be started or the work can be outsourced to a service company that is capable of providing the necessary skills and techniques.

The frequency of conduct of maintenance activities has to be linked to realistic mean time between failures. Moreover, functionality and performance degradation of the equipment has to be monitored in a manner that sufficient time is available for the maintenance managers to plan and organize selected maintenance activity execution. The subsystems and components will have different deterioration processes depending on their construction, materials, usage, and exposure to external conditions. Deterioration may be modelled based on failure characteristics and operating environmental characteristics; i.e., modeling deterioration in terms of a time-dependent stochastic process [21]. Relevant models are, for example, the P-F interval, proportional hazard modeling (PHM) - a multivariate regression analysis and Markov-processes [22].

The other method to estimate equipment degradation is by use of condition monitoring techniques such as vibration monitoring (e.g. belt, gear drive, or surfaces with components with relative motion), temperature (e.g. electrical components, bearing houses, hydraulic pumps, etc.), lubricant monitoring (transmission components like gears, cams, bearings). The operating context is an important factor, which influences degradation and can be classified into three operating regimes, namely, normal, marginal and hostile operating contexts [23]. Under the influence of operating context, condition levels are modulated, thereby true level of degradation cannot be inferred by mere trending of condition indicator's level. Hence, operating context needs to be considered while using condition indicator level to infer state of equipment.

\section{Discussion and Concluding Remarks}

Basing preventive maintenance on time and usage intervals alone may no longer be the best practice and an optimized way of developing maintenance programs. In general, the preventive maintenance programs are developed in the pre-operation stages, and the information from the condition monitoring is received in the operation stages.

Condition based maintenance (CBM) can in principle help in improving the effectiveness and efficiency of predetermined periodic maintenance strategies, but the industry faces challenges in effectively implementing the CBM. Moreover, the challenge is to integrate the information available from the condition monitoring sources as well as from the preventive maintenance plans to improve the effectiveness and efficiency of the maintenance programs [24].

The process of integrating the condition monitoring should be planned in the preoperation stages. The maintenance engineers responsible for the development of maintenance programs should be able to foresee and plan the integration of likely condition monitoring information available in the operations stage. By identifying opportunities to include real-time condition data, the preventive maintenance routines based on fixed schedules should become more dynamic, and equipment health should improve. 
However, today the information from sensor technology is mainly utilized for better and safe control of operations. Measurements such as flow, pressure and temperature assist in control of the processes, and most of the process shutdowns, emergency shutdowns and equipment shutdowns are conducted through the control rooms by use of the sensor technology. The same sensors may be used to gain information of the health of the equipment and the performance degradation processes, but, as mentioned, the integration of such vital process information in maintenance management is still a challenge.

The main focus of any production company is to strive towards minimizing their failure rate and downtime in order to maximize production - without production no income is generated, but expenses are still running for the company. The actual cost of equipment downtime may be more than that of the repair and maintenance work, spare parts and the maintenance logistics and administration.

If failure occurs at a time where the market value of the product or the production itself is high, the financial disadvantages will be larger than if one can plan and executed a maintenance task at times with reduced production. In order to minimize the cost of downtime and failures, maintenance management is important, and activities must be carefully planned and executed to occur at a specific time, when the cost of production downtime is the least.

Thus arises the classic dilemma within maintenance: as the operation crew craves maximum uptime in order to produce as much as possible, the maintenance crew craves more downtime in order to provide better care for the equipment. To balance the internal differences, maintenance strategies are based on the company's goals and objectives, and activities are planned and scheduled based on the available technology and nature of the equipment.

The industrial maintenance practices can be considered a result of the mixture of the industrial and academic research and development. The maintenance strategies must encompass the financial demands for effectiveness and the overall safety standards, and are subject to change as the technology progresses. By combining the benefits from predictive and preventive maintenance, a more knowledge-based approach to maintenance can be achieved. However, this is rarely seen in the industry, where the two strategies often coexist without merging.

\section{References}

1. Tsang, A.H.C.: Condition-based maintenance: tools and decision making. Journal of Quality in Maintenance Engineering 1, 3-18 (1995)

2. Tsang, A.H.C., Yeung, W.K., Jardine, A.K.S., Leung, B.P.K.: Data management for CBM optimization. Journal of Quality in Maintenance Engineering 12, 37-51 (2006)

3. Dhillon, B.S.: Reliability-centered maintenance - engineering maintainability. Gulf, Houston (1999)

4. Kans, M.: The advancement of maintenance information technology - a literature review. Journal of Quality in Maintenance Engineering 15, 5-16 (2009)

5. Campos, J.: Development in the application of ICT in condition monitoring and maintenance. Computers in Industry 60, 1-20 (2009)

6. Ravnestad, G.: Integration of condition monitoring data to preventive maintenance activities: Issues, opportunities and challenges. Master thesis, University of Stavanger, Norway (2010) 
7. Levitt, J.: Complete guide to preventive and predictive maintenance. Industrial Press, New York (2003)

8. Wireman, T.: Preventive maintenance. Industrial Press, New York (2008)

9. Löfsten, H.: Management of industrial maintenance \pm economic evaluation of maintenance policies. Int. Journal of Operations \& Production Management 19, 716-737 (1999)

10. Mobley, R.K.: Designing a preventive maintenance program - maintenance fundamentals, 2nd edn. Butterworth-Heinemann, Burlington (2004)

11. Eti, M.C., Ogaji, S.O.T., Probert, S.D.: Reducing the cost of preventive maintenance (PM) through adopting a proactive reliability-focused culture. Applied Energy 83, 1235-1248 (2006)

12. Rao, B.K.N.: Condition monitoring - The way forward - handbook of condition monitoring. Elsevier, Oxford (1996)

13. Beebe, R.S.: Predictive maintenance of pumps using condition monitoring. Elsevier, Oxford (2004)

14. Stacey, A., Sharp, J.V.: Safety factor requirements for the offshore industry. Engineering Failure Analysis 14, 442-458 (2007)

15. Panesar, S.S., Kumar, R., Markeset, T.: Development of maintenance strategies for offshore production facilities. In: The Proceedings of the 3rd World Congress on Engineering Asset Management and Intelligent Maintenance Systems (WCEAM-IMS 2008), Beijing, China, October 28-30, pp. 1227-1232 (2008) ISBN 978-1-84882-216-0

16. Piotrowski, J.: Effective predictive and pro-active maintenance for pumps. Maintenance World (2007)

17. Markeset, T.: Design for production performance in Arctic locations considering maintenance and support services. In: The Proceedings of the Mine Planning and Equipment Selection Conference (MPES 2008), Beijing, China, October 20-22 (2008)

18. NORSOK Z008 Criticality analysis for maintenance purposes. Norwegian Technology Centre (2001), http: / / www . standard. no/PageFiles / 961/Z-008.pdf (accessed June 2)

19. Conachey, R.M., Montgomery, R.L.: Application of reliability-centered maintenance techniques to the marine industry. SNAME, Texas Section (2003)

20. Markeset, T., Kayrbekova, D.: Capacity-driven, activity-based life-cycle costing in strategic maintenance decision-making: modeling the cost of performance. To appear in Journal of Quality in Maintenance Engineering (2012)

21. Moubray, J.: Reliability-centered maintenance. Butterworth-Heinemann, Oxford (1997)

22. van Noortwijk, J.M.: A survey of the application of gamma processes in maintenance. Reliability Engineering and System Safety 94(1), 2-21 (2009)

23. Edwin, V.K., Chaturvedi, S.K.: Application of predictive maintenance techniques for failure rate modelling of electric motors in process industry. In: The Proceedings of the International Conference on Reliability and Safety Engineering, INCRESE 2006 (2006)

24. Saranga, H.: Relevant condition-parameter strategy for an effective condition-based maintenance. Journal of Quality in Maintenance Engineering 8, 92-105 (2002) 